\title{
UPAYA PENERAPAN IMAJINASI TERBIMBING UNTUK MENURUNKAN TEKANAN DARAH PADA PASIEN HIPERTENSI
}

\author{
Baik Heni Rispawati $^{{ }^{*}}$, Dewi Nursukma Purqoti ${ }^{2}$ Ernawati $^{3}$, Supriyadi ${ }^{4}$ \\ ${ }^{1-4}$ STIKES Yarsi Mataram
}

Email Korespondensi: baiqhenirispawati123@gmail.com

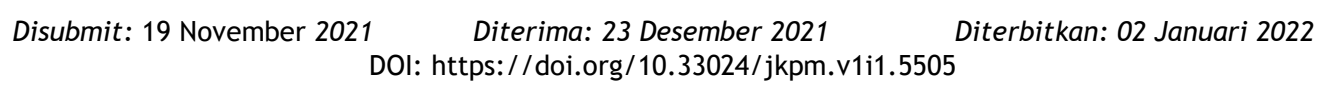

\begin{abstract}
ABSTRAK
Data world health organization (WHO) menunjukkan sekitar 1,13 Miliar orang di dunia menyandang hipertensi, artinya 1 dari 3 orang di dunia terdiagnosis hipertensi. Hipertensi disebut sebagai silent killer karena pada sebagian besar kasus tidak menunjukkan tanda dan gejala apapun, sehingga penderita tidak mengetahui jika dirinya terkena hipertensi. Tujuan Setelah diberikan penerapan imajinasi terbimbing diharapkan adanya perubahan tekanan darah pada penderita yg mengalami hipertensi pada Lansia dan mengetahui cara mengatasi hipertensi tanpa menggunakan obat. Pelaksanaan kegiatan ini dengan cara melakukan sebelumnya pengukuran tekanan darah pada lansia selanjutnya melakukan imajinasi terbimbing. Ditemukan lansia menderita hipertensi tetapi blm tau cara pengobatan menggunakan non farmakologi dan Imajinasi Terbimbing ini belum pernah diterapkan di Desa lingsar. Dengan demikian program kesehatan ini sangat mendukung dan sangat efektif untuk dilakukan khususnya kegiatan Imajinasi Terbimbing ini agar dapat dijadikan sebagai program rutin seperti sosialisasi, program kesehatan. Pelaksanaan Imajinasi Terbimbing Ini sangat bagus untuk menurunkan tekanan darah pada pasien Hipertensi. Oleh karena itu perawat di Puskesmas juga dapat mengaplikasikan teknik Imajinasi Terbimbing dalam membantu menurunkan tekanan darah pada pasien yang mengalami hipertensi
\end{abstract}

Kata Kunci: Imajinasi Terbimbing, Tekanan Darah, Pasien Hipertensi

\begin{abstract}
World Health Organization (WHO) data shows approx 1.13 billion people in the world have hypertension, meaning that 1 in 3 people in the world is diagnosed with hypertension. Hypertension is called the silent killer because in most cases it does not show any signs and symptoms, so the patient does not know if he has hypertension. Objectives After being given the application of guided imagination, it is hoped that there will be changes in blood pressure in patients who have hypertension in the elderly and know how to treat hypertension without using drugs. The implementation of this activity is done by first measuring blood pressure in the elderly and then doing guided imagination. It was found that the elderly suffered from hypertension but did not know how to use non-pharmacological treatment and this Guided Imagination had never been applied in Lingsar Village. Thus this health program is very supportive and very effective to be carried out, especially this Guided Imagination activity so that
\end{abstract}


it can be used as a routine program such as socialization, health programs. Implementation of Guided Imagination This is very good for lowering blood pressure in Hypertensive patients. Therefore nurses at the Puskesmas can also apply the Guided Imagination technique to help lower blood pressure in patients with hypertension

\section{Keywords: Guided Imagination, Blood Pressure, Hypertension Patients}

\section{PENDAHULUAN}

Data world health organization (WHO) tahun 2015 menunjukkan sekitar 1,13 Miliar orang di d unia menyandang hipertensi, artinya 1 dari 3 orang di dunia terdiagnosis hipertensi. Data world health organization (WHO) tahun 2015 prevalensi tertinggi peningkatan tekanan darah usia > 18 terdapat di Afrika sebesar 30\%, Jumlah hipertensi di dunia terus meningkat setiap tahunnya, diperkirakan pada tahunnya. Diperkirakan tahun 2025 akan ada 1,5 miliar orang yang terkena hipertensi.

Hipertensi merupakan suatu kondisi tekanan darah yang melebihi batas normal, yakni sistolik $\geq 140 \mathrm{mmHg}$ dan diastolik $\geq 90 \mathrm{mmHg}$, tekanan darah normal manusia adalah $120 / 80 \mathrm{mmHg}$. Umumnya penderita tidak menyadari jika dirinya menderita hipertensi, karena hipertensi seringkali tanpa tanda dan gejala, hipertensi sering disebut sebagai silent killer (WHO, 2015).

Menurut Rikesdas (2018) menyatakan prevalensi hipertensi berdasarkan hasil pengukuran pada penduduk Indonesia sebesar 63.309 .620 orang, sedangkan angka kematian di Indonesia sebesar 427.218 kematian. Hipertensi terjadi pada kelompok umur 31-44 tahun (31,6\%), umur 45-54 tahun( 45,3\%), umur 55-64 tahun (55,2\%). Di perkirakan tahun 2025 indonesia akan mengalami peningkatan. Menurut Rikesdas (2018) diperkirakan penderita hipertensi usia > 18 tahun di provinsi Nusa Tenggara Barat sebanyak 358.110 jiwa dan pada daerah Lombok barat sebesar $0,9 \%$.

Menurut data tahun 2018 yang didapatkan di Puskesmas Lingsar lansia yang mengalami hipertensi selama 3 bulan terakhir didapatkan pada bulan Agustus 96, bulan September 134, dan bulan oktober 124 orang yang mengalami hipertensi dari jumlah data tersebut lebih banyak perempuan karena lebih banyak perempuan yang datang posyandu lansia dari pada laki- laki karena jarang melakukan posyandu lansia.

Hipertensi termasuk masalah yang besar dan serius karena sering tidak terdeteksi meskipun bertahun-tahun. Ketika gejala timbul, hipertensi sudah menjadi penyakit yang harus diterapi seumur hidup, pengobatan yang harus di keluarkan cukup mahal dan membutuhkan waktu yang lama. Bila tidak ditangani dengan baik akan menimbulkan masalah lain berupa komplikasi berbagai organ jantung, ginjal, otak, mata. Hipertensi juga dapat menyebabkan kecacatan permanen dan kematian mendadak. Penyakit hipertensi pada lansia memerlukan penangan tanpa menimbulkan efek samping yang bertujuan untuk mencegah terjadinya morbiditas dan mortalitas serta mempertahankan tekanan darah normal. (Sumartini \& Bachtiar, 2016)

Pengobatan dapat dilakukan dengan dua cara bisa dengan cara Farmakologi dan nonfarmakologis, pendekatan secara farmakologis dapat dilakukan dengan pemberian antihipertensi. Walaupun antihipertensi sangat efektif untuk menurunkan tekanan darah, namun hal tersebut akan berdampak kecanduan obat dan akan memberikan efek samping obat yang berbahaya bagi pasien. Salah satu efek samping penggunaan antihipertensi dalam jangka waktu 
yang lama adalah batuk, batuk sering dikeluhkan oleh penderita hipertensi dengan mengonsumsi captopril.(Aswad, 2019)

Manajemen non farmakologi dapat dilakukan salah satunya dengan teknik imajinasi terbimbing,tehnik imaginasi terbimbing ini merupakan teknik relaksasi dengan menggunakan imajinasi seseorang dengan satu cara yang dirancang secara khusus untuk mencapai efek tertentu, pada teknik ini stimulasi otak melalui imajinasi dapat menimbukan pengaruh langsung pada system saraf, endokrin, neuromodulator, endorphin dengan cara mampu menurunkan frekuesi hart rate sehingga cardiac output akan sesuai dengan normal ritme. (Aswad, 2019).

Permasalahannya di desa lengsar banyak warga mengeluh hipertensi, maka dalam kesempatan ini peneliti ingin mencoba memperkenalkan salah satu pengobatan hipertensi secara nonfarmakologis yaitu penerapan tehnik imajinasi terbimbing yang bertujuan untuk menurunkan tekanan darah pada lansia penderita hipertensi dan untuk meningkatkan pengetahuan warga desa Lingsar tentang penyakit Hipertensi dan dapat menerapkan secara mandiri tehnik imajinasi tersebut. Pengabdian ini dilakukan di Desa lingsar, dimana didapatkan data sebagian besar warga menderita Hipertensi

\section{MASALAH}

Alasan Kami memilih tempat pengabdian tentang imajinasi terbimbing di desa Lingsar wilayah kerja puskesmas Lingsar terdapat beberapa lansia mengatakan mengalami tekanan darah tinggi tetapi penanganannya mereka mengatakan menggunakan obat saja, mereka belum mengetahui tentang pengobatan secara non farmakologis, Upaya untuk mengatasi dan mencegah dampakburuk diperlukanpenanganan terkait. Upaya yang telah dilakukan dalam pencehagan dan pengendalian hipertensi sehingga banyak orang menganggap hipertensi hanya bisa ditangani dengan pengobatan obat saja atau farmakologi, Padahal bisa ditangani dengan pengobatan non farmakologi juga. Salah satu yang bisa dilakukan untuk menurunkan hipertensi yakni tehnik imaginasi terbimbing. Tehnik imajinasi terbimbing merupakan salah satu cara terbaik untuk menurunkan tekanan darah. Dengan tehnik imaginasi yang dilakukan secara teratur dapat menurunkan tekanan darah sistolik dan diastolic, menurunkan kadar hormone stress cortisol, menurunkan kecemasan sehingga tekanan darah akan turun dan fungsi tubuh semakin membaik. (Aswad, 2019).

Dilokasi pengabdian sebagian besar warga termasuk dalam taraf ekonomi menengah ke bawah, sehingga dari pendapatan masyarakat yang tidak pasti. sebagian besar berprofesi sebagai petani dan pedagang. Untuk pendidikan masyarakat masih banyak yang tidak melanjutkan pendidikan dengan berbagai alasan salah satunya masalah ekonomi. Salah satu cara yang cukup untuk bisa mengatasi tekanan darah tinggi dalam pengabdian ini diberikan pilihan dalam kegiatan pengabdian ini adalah penerapan tehnik imajinasi terbimbing yang bisa diterapkan masyarakat tentang pengenalan konsep dasar penyebab,tanda dan gejalapencegahan serta penanganan non farmakologi berupa tehnik imajinasi terbimbing untuk menurunkan tekanan darah. Tujuan Pengabdian masyarakat di Desa Lingsar bertujuan agar masyarakat memiliki pemahaman dasar tentang cara penanganan Hipertensi, serta mampu menerapkan intervensi non farmakologis untuk 
menurunkan tekanan darah.

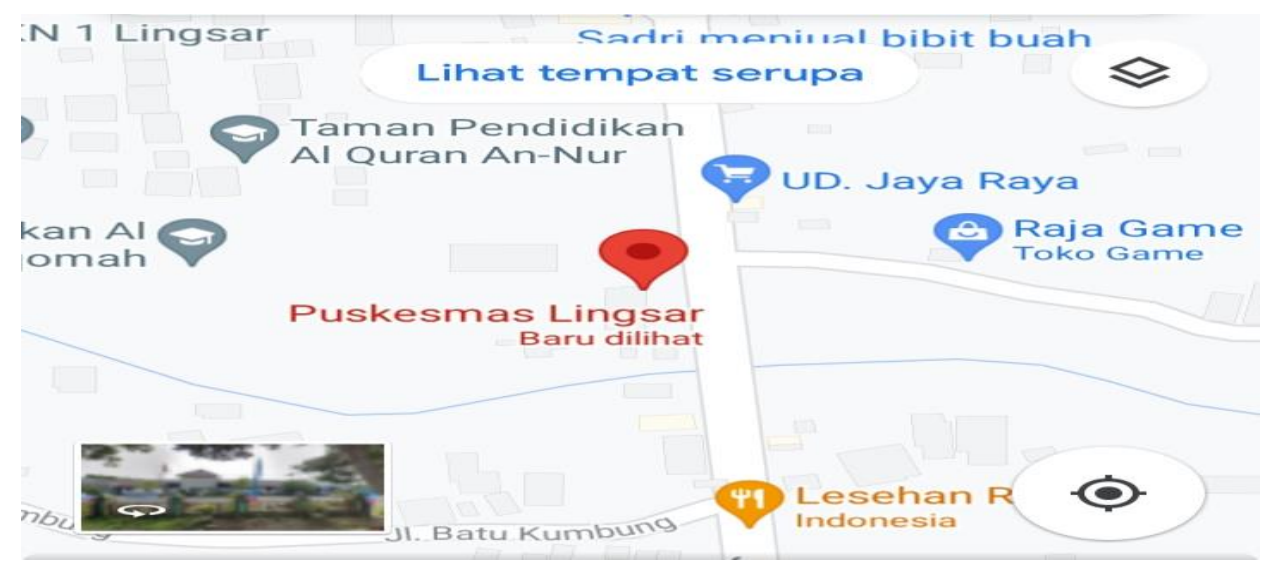

Gambar 2.1 Lokasi Penerapan Imaginasi Terbimbing

\section{METODE}

\section{a. Tujuan Persiapan}

Pengabdian masyarakat di desa Lingsar wilayah kerja puskesmas Lingsar bertujuan agar masyarakat memiliki pemahaman dasar tentang Hipertensi, serta mampu menerapkan intervensi non farmakologis untuk menurunkan tekanan darah dengan tehnik imajinasi Terbimbing, Persiapan pelaksanaan tenik imaginasi terbimbing ini dimulai tanggal 4 November 2021.

Pengabdian kepada masyarakat ini telah dilaksanakan pada hari kamis, 4 November 2021 dimulai sejak pukul 09.00- selesai di rumah salah satu kader kesehatan di desa Lingsar wilayah kerja puskesmas Lingsar ,Dengan target sasaran mencapai 16 Orang. Sebelum pelaksanaan kegiatan dilakukan terlebih dahulu observasi lokasi pada tanggal 1 Oktober 2021 Persiapan kegiatan dilakukan dengan melakukan koordinasi dengan pihak puskesmas kepala desa Lingsar untuk persiapan tempat pelaksanaan kegiatan.

Solusi yang cukup strategis yang ditawarkan dalam kegiatan pengabdian ini adalah peningkatan pemahaman masyarakat terutama lansia yang mengalami hipertensi memahami tentang pengenalan konsep dasar penyebab, tanda dan gejala, cara pencegahan dan penanganan hipertensi dengan cara non farmakologi berupa tehnik imajinasiterbimbing untuk menurunkan tekanan darah.

\section{b. Tahap pelaksanaan}

Sebelum Pelaksanaan kegiatan pengabdian dilakukan koordinasi kepada pihak puskesmas Lingsar dan kader dan lansia di desa Lingdsar kemudian dilanjutkan dengan pelaksanaan tehnik Imajinasi Terbimbing.

Adapun metode pelaksanaan kegiatan pengabdian ini adalah: 


\section{a. Pre Test}

Dilakukan pengkajian terhadap pengetahuan warga tentang penyakit

Hipertensi, pengkajian yang dirasakan dan pengukuran tekanan darah menggunakan alat spigmomanometer dan lembar observasi sebelum dilakukan tenik imajinasi terbimbing.

b. Pemaparan Materi

Pada pemaparan materi diberikan pengertian hipertensi, penyebab, tanda dan gejala, cara pencegahan serta penanganan non farmakologi dengan metode ceramah dan diskusi. Setelah pemaparan materi tentang tehnik imajinasi terbimbing,selanjutnya dilakukan diskusi. Warga dipersilahkan untuk bertanya tentang hal-hal yang belum dipahami terkait materi penyuluhan.

\section{c. Masase Kepala}

Setelah pemaparan materi selanjutnya bersama-sama warga melakukan latihan terapi tehnik imajinasi terbimbing dengan waktu 515 menit

d. Post Test

Pada tahap ini dilakukan pengkajian kembali pemahaman warga

mengenai Hipertensi setelah diberikan waktu istirahat selama 10 menit setelah dilakukan tehnik imajinasi terbimbing dan dilakukan pengukuran tekanan darah postest intervensi

e. Monitoring dan Evaluasi

Pada tahap ini tim pengabdian masyarakat melakukan evaluasi dan monitoring terhadap monitoring kembali dilakukan 4 minggu setelah pelaksanaan pengabdian masyarakat. Saat monitoring, dilakukan pula pengkajian terhadap keluhan yang dirasakan warga sebagai evaluasi setelah menerapkan secara mandiri tehnik imajinasi terbimbing

\section{c. Evaluasi}

\section{i. Struktur}

Pada tahap ini warga yang hadir sebanyak 16 orang lansia penderita hipertensi yang terdiri dari laki-laki dan perempuan, tempat sudah dipersiapkan sesuai planing yang ditentukan yakni di desa lingsar. Adapun peran yang bertanggung jawab yang menyampaikan materi, tehnik imajinasi, sebagai moderator, notulen, observasi, pendokumentasian sudah ditetapkan.

\section{ii. Proses}

Pelaksanaan kegiatan pukul 10.00 s/d 12.30 WITA. Sesuai dengan jadwal yang telah direncanakan.

iii. Hasil

1. Penderita hipertensi memahami dan mengerti tentang pengertian hipertensi

2. Penderita hipertensi memahami dan mengerti tentang penyebab hipertensi

3. Penderita hipertensi memahmi dan mengerti tentang tanda dan gejala hipertensi Penderita hipertensi memahami dan mengerti tentang penatalaksaan menurunkan tekanan darah hipertensi menggunakan terapi non farmakologis. 
4. HASIL DAN PEMBAHASAN

Dari hasil pengabdian pada warga hipertensi di desa lingsar puskesmas lingsar didapatkan hasil bahwa setelah dilakukan tindakan tehnik imajinasi terbimbing didapatkan hasil lansia bahwa tejadi perbedaan tingkat tekanan darah sebelum dan setelah dilakukan tindakan teknik inmajinasi terbimbing, terjadi penurunan tekanan darah yang signifikan setelah diberikan tindakan teknik imajinasi terbimbing pada lansia yang megalami hipertensi,dimana dapat dilihat dari hasil pengukuran tekanan darah sebelum dilakukan tindakan imajinasi terbimbing didapatkan pengukuran tekanan darah rata-rata 180/110 mmhg mengalami hipertensi berat. Sedangkan setelah dilakukan tindakan tehnik Imajinasi Terbimbing didapatkan hasil pengukuran tekanan darah mengalami perubahan menjadi rata-rata $120 / 80 \mathrm{mmhg}$, dimana dapat dilihat perbedaan hasil sebelum dan sesudah dilakukan tehnik imajinasi terbimbing.

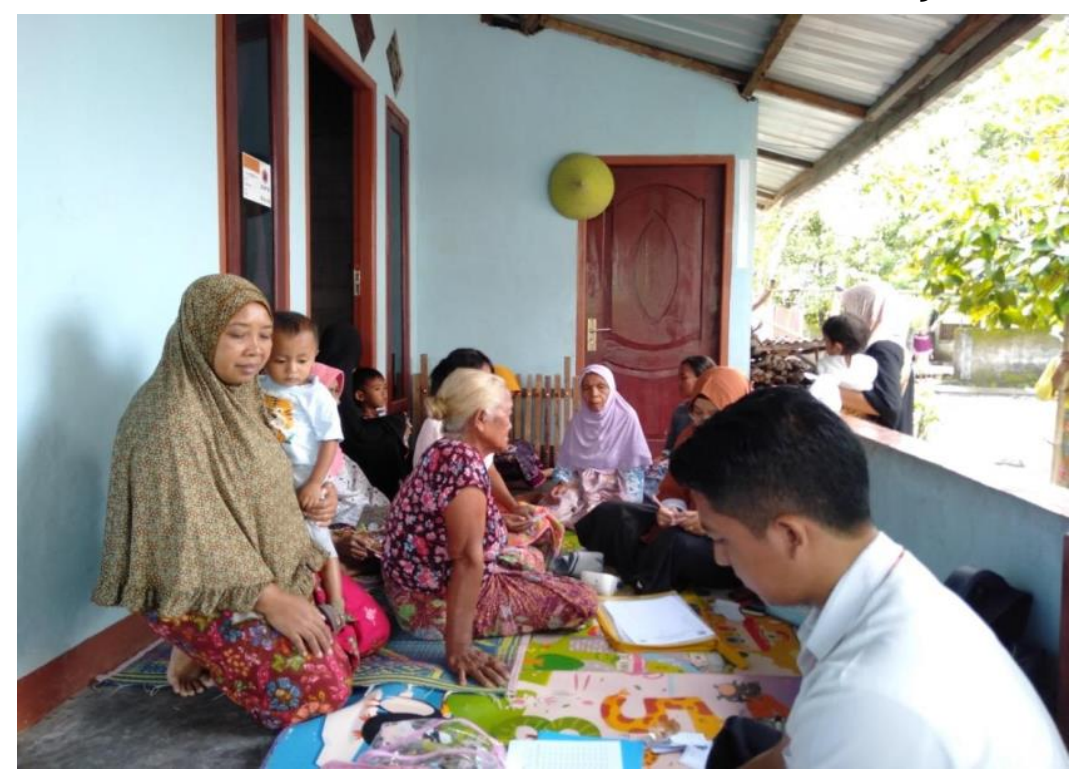

Gambar 2.2 Foto Kegiatan Pengabdian

\section{KESIMPULAN}

Berdasarkan kegiatan yang dilakukan, maka dapat disimpulkan sebagai berikut : Rata-rata peserta kegiatan pengabdian masyarakat berusia di atas 45 sampai dengan 60 tahun, Adanya peningkatan pemahaman tentang Hipertensi dan mengerti tentang pengobatan dengan cara non farmakologis pada warga desa lingsar terbukti denagan adanya hasil penurunan tekanan darah pada warga yang mengalami hipertensi setelah dilakukan tehnik imajinasi terbimbing. 


\section{DAFTAR PUSTAKA}

Agus, R. (2011). Aplikasi Metodelogi Penelitian Kesehatan. Yogyakarta : Nuha Medika.

Apiani Reny Yuli. (2014). Asuhan Keperawatan Gerontik. CV Trans Info Media.

E Bustami dkk. (2020). Hubungan Pengetahuan tentang hipertensi dengan penatalaksanaan penyakit hipertensi Non farmakologi (diet rendah garam) di Puskesmas Sei Langkai.

Hidayat, limul Aziz. (2017). Metodelogi Penelitian dan Kesehatan. Selamba Medika. Jakarta.

Kementrian kesehatan republik Indonesia. http//www.p2ptm.kemkes.go.id Data dan informasi profil kesehatan

Lorna Lolo Lestari, Novianty Nensi. (2018). Pengaruh Pemberian Guided Imagery Terhadap Skala Nyeri Pada Pasien Post Operasi Appendisitis Hari Pertama Di RSUD Sawerigading Kota Palopo. Volume 01. Jurnal Fenomena Kesehatan.

Mahanani Srinalesti, Yusiana Maria Anita. (2017). Terapi Imajinasi terbimbing. Adjie Media Nusantara.

Noviyanti. (2015). Hipertensi Kenali, Cegah \& Obati. Yogyakarta : Notebook

Yusrin Aswad, Budi Santoso. (2019). Pengeruh Imajinasi Tterbimbing Terhadap Tekananan Darah Penderita Hipertensi di Panti Wirda Ilomata.Vol 1, No 1. Jambura Journal of Health Sciences and Research.

Nursalam. (2013). Konsep Penerapan Metode Penelitian Ilmu keperawatan. Jakarta: Selamba Medika.

Prasetyaningrum yunita indah. (2014). Hipertensi Bukan untuk ditakuti. Fmedia

Setyani, Hanan Iko. Dkk. (2019). Pengaruh Terapi Guided Imagery Terhadap Penurunan Tekanan Darah Pada Pasien Hipertensi. Vol.6 No 2. Jurnal Ners Widya Husada Semarang.

Sumarliyah, Eni. (2018). Penurunan Tekanan Darah Dengan Relaksasi Autogenik Dan Guided Imagery Pada Pasien Hipertensi. Vol.4.No2.Fakultas IImu Kesehatan, Muhammadiyah Surabaya .

Sumartini Sri, Bachtiar Heru Hari. (2016). Perbedaan Tekanan Darah Sebelum dan Sesudah Pemberian Teknik Relaksasi Imajinasi Terbimbing Pada Lansia Yang Menderita Hipertensi. Vol.2 No.1. Jurnal Keperawatan Indonesia.

WHO. (2015). Data WHO 2018 tentang hipertensi. Diakses pada tanggal 15 Februari 2019 jam 15.17 wita.

Zainaro, M. A., Chrisanto, E. Y., \& Perkasa, A. W. (2021). Asuhan keperawatan komprehensif dengan penerapan efektifitas foot massage dan progressive muscle relaxation terhadap penurunan tekanan darah pada penderita hipertensi. JOURNAL OF Public Health Concerns, 1(3), 151-161. 